\title{
CI. THE ACTION OF DYESTUFFS ON ENZYMES.
}

\section{FUMARASE.}

\author{
By JUDA HIRSCH QUASTEL. \\ From the Biochemical Laboratory, Cardiff City Mental Hospital.
}

(Received May 5th, 1931.)

IT has been shown in an earlier communication [Quastel and Wheatley, 1931] that there is a marked difference of behaviour between the various dyestuffs in their effects upon the oxidations of bacteria and tissues. Whereas certain dyestuffs such as ethyl violet or malachite green will eliminate almost entirely the ability of bacteria to oxidise such substrates as glucose, succinate, lactate or formate, others, e.g. Congo red, crystal scarlet, are inert. It is among the basic dyestuffs that the greatest toxicity is discernible; the acid dyestuffs appear to be comparatively inactive under the conditions employed. Not only, however, does the basic nature of the molecule play an important part in determining its toxic action; its molecular structure is of equal importance. It has been shown, too, that toxicity of a dyestuff towards oxidations is greatly influenced by the presence of substances which appear to have little to do with the oxidations themselves. Methylene blue, for instance, is much less toxic to the oxidation of succinate by bacteria or muscle in the presence of phosphates than in the presence of glycine or veronal at the same $p_{\mathrm{H}}$, and it can be shown that bacteria 'poisoned' by methylene blue in the presence of veronal and unable to take up oxygen, will once again respire on the addition of phosphates. Phosphates appear to be able to combine with the dyestuff and to elute it from its combination with the oxidising system.

It is now proposed to describe the effects of dyestuffs on an enzyme, fumarase, which has a wide biological distribution. It is found in considerable amount in yeast, most forms of bacteria, red blood corpuscles, moulds, certain parts of plants and most animal tissues. The enzyme is entirely intracellular and it is owing to this fact and the circumstance that certain cells are not freely permeable to the fumarate molecule, that it is easy to make a wrong estimate of the total quantity of fumarase in the cell. Fumarase has been chosen for study not only because of the relative simplicity of the easily reversible hydrolytic reaction which it brings about but also because the experimental technique involved is simple and the effects of dyestuffs upon it can be determined with considerable accuracy.

Dyestuffs show a specificity of behaviour towards fumarase which is much 
greater than that displayed towards the oxidations already referred to. Both basic and acid dyestuffs have toxic effects on the enzyme, a specificity of behaviour with both types of dyestuff being observable. The specificity, however, among the acid dyestuffs, is most marked-whereas, for instance, two such acid dyestuffs as crystal scarlet and orange $G$ have no inhibiting action. Congo red is toxic at a molar concentration of $1 \cdot 2 \times 10^{-8}$.

\section{Preparation of fumarase.}

(a) From B. coli. It was shown in the first place by Quastel and Whetham [1924] that fumarase occurred in the cells of $B$. coli. Its action, however, was masked by the presence of reducing systems in the cell. When these systems were inactivated by growth inhibitors such as toluene or propyl alcohol the enzyme could be demonstrated in relatively large quantity [Woolf, 1929]. As will be shown later, however, it is necessary, in order to study the effects of certain substances on fumarase, to have a preparation of the enzyme free from the cell. This preparation can be made in the case of $B$. coli in the following way.

B. coli is grown in tryptic broth or on nutrient agar plates for 48 hours and the organism centrifuged from the broth or scraped from the plates with the addition of a little normal saline. It is washed twice with saline to remove extraneous material as far as possible and finally made up into a thick suspension with saline. To this suspension is added four times its volume of $1 \%$ $\mathrm{Na}_{2} \mathrm{HPO}_{4}$, and this is allowed to stand in the incubator at $37^{\circ}$ for three days. The suspension is now centrifuged and the centrifugate, which is slightly opalescent, mixed with a little kieselguhr and filtered. The clear filtrate contains the enzyme. It should be neutralised with a little acid and stored at $0^{\circ}$. (This preparation not only contains fumarase, but it has the property of transforming fumarate into $l$-aspartate in the presence of ammonium ions.)

(b) From M. lysodeikticus. If a washed suspension of this organism (prepared from a growth on agar plates) be mixed with fumarate in phosphate buffer and allowed to stand at $45^{\circ}$ for six hours, little or no transformation into $l$-malate occurs. There would appear to be little or no fumarase present. If, however, as was shown by Penrose and Quastel [1930], the suspension of the organism be first lysed by the addition of saliva or a little egg-white, a rapid transformation of fumarate into $l$-malate takes place, the breakdown of the cell membrane bringing about a ready access of fumarate to the enzyme. Neither saliva nor egg-white enhances the activity of the cell-free enzyme. A method, therefore, of obtaining fumarase free from the cell is to lyse $M$. lysodeikticus, to centrifuge the solution after lysis and to filter the centrifugate after admixture with a little kieselguhr. The clear filtrate contains the enzyme, and more active preparations can be made in this way than by the method described for $B$. coli. The method, moreover, is far quicker, for the lysis of the organism takes place in a few minutes at $37^{\circ}$ or $45^{\circ}$. The preparation is 
practically free from phosphates and is convenient for the study of the actions of phosphates and salts on the enzyme.

(c) From red blood corpuscles. Clutterbuck [1928] reported that defibrinated ox blood showed a slight fumarase activity. This, I have found to be also the case with human, rabbit, or guinea-pig blood. Incubation of whole blood or a washed suspension of blood corpuscles with fumarate at $45^{\circ}$ for several hours results only in a slight transformation into $l$-malate. If, however, the red blood cells be first lysed with distilled water then, just as in the case of the lysis of $M$. lysodeikticus, there is a most rapid transformation of fumarate into $l$-malate. Human blood proves, indeed, to be one of the richest sources of fumarase. (Further details of this, together with other facts concerning the biological distribution of fumarase, will be reserved for another communication.) The fumarase obtained from blood is accompanied by much protein, and this greatly affects results carried out with dyestuffs, etc.

(d) From brain. In estimating the effects of dyestuffs, etc. on fumarase it is of great importance to have a preparation of the enzyme which is reasonably free from protein and phosphates and which can be kept, as a standard preparation, for several months without losing its activity. None of the methods described above is particularly suitable. To obtain fumarase from bacteria involves the tedious procedure of preparing growths of the organisms, with subsequent lysis or autolysis, and the activities of the preparations are somewhat variable, depending upon the strain of the organism, effectiveness of lysis, etc.

Attempts were made to make a standard preparation from muscle but, although very active extracts were made, it was difficult to obtain a reasonably protein-free preparation which would keep for any length of time.

Finally the problem was solved by preparing the enzyme from brain. It is known that the enzyme occurs in brain, but perhaps it is not so well known that the white matter of brain is even richer in the enzyme than the grey. The whole brain, therefore, was used for the following preparation of fumarase.

The brain of an animal (I have used both sheep and human brain) is freed from the membranes and minced twice. To the minced brain is added twice its volume of $1 \% \mathrm{Na}_{2} \mathrm{HPO}_{4}$, and the suspension is well shaken mechanically for an hour. The resultant creamy liquid is filtered through muslin, and an equal volume of saturated ammonium sulphate solution is added and the suspension well stirred and allowed to stand overnight. A firm clot of protein, rich in fumarase, appears at the surface. This is poured on to muslin, which retains the clot. The clot in the muslin is allowed to drain for 24 hours and can be squeezed to facilitate the draining. Finally it is rapidly washed with water. (This clot may be suspended in water, which takes much of it into solution, and reprecipitated with saturated ammonium sulphate-the operation described above being repeated.)

The clot, which is of slimy consistency, is spread evenly over a glass plate and about twice its weight of plaster of Paris mixed with it. An even mixing 
should be made so that the heat evolved, as the preparation dries, is quickly dissipated. Usually the preparation as a whole, if properly mixed and broken, does not become more than just warm-the temperature should not be allowed to become high enough to cause destruction of the enzyme.

The plaster of Paris preparation takes up water rapidly and should be stored in a refrigerator kept at $0^{\circ}$ or slightly below $0^{\circ}$. I have found that this preparation will retain its fumarase activity for six months.

$20 \mathrm{~g}$. of the preparation is mixed with $100 \mathrm{cc}$. distilled water and well shaken in a machine for an hour. This is centrifuged and the slightly opalescent centrifugate is treated with a few cc. of $M / 2$ potassium oxalate solution to precipitate all the calcium present. About $5 \mathrm{~g}$. of kieselguhr are added to the suspension, which is shaken by hand for a few minutes and filtered. A perfectly clear filtrate with high fumarase activity is formed - this contains only slight traces of phosphate and protein. It is important, when eluting the enzyme from the plaster of Paris preparation, to use distilled water and not saline or phosphate or bicarbonate solutions. If the latter are used, preparations richer in fumarase are formed, but large quantities of protein are also taken into solution.

Fumarase preparations made in this way have remarkably constant fumarase activities, fresh extracts made every two or three days over a period of several weeks not varying in activity more than 5 or $6 \%$.

The plaster of Paris preparation may be extracted in a Soxhlet with ether without appreciably diminishing its fumarase activity - I have found, however, for my purposes, that the ether extraction is unnecessary.

This plaster of Paris preparation will be referred to in the remainder of this paper as the brain preparation.

\section{Estimation of fumarase activity.}

The estimation of $l$-malic acid may be easily accomplished by means of the polarimeter. Malic acid gives in acid solution and in the presence of molybdate a complex ion having very high rotatory power. Full details of the molybdate method of estimating $l$-malic acid are given by Auerbach and Kruger [1923]. These workers also describe the influence of various (not polarimetrically active) substances on the malic-molybdate complex. Citrates, for example, should not be present as they have the effect of greatly increasing the rotation. (This fact was not taken into account in the work of Mann and Woolf [1930] on the effects of citrates on fumarase activity and, in consequence, it is very difficult to interpret their results.)

I have made it a routine to take $5 \mathrm{cc}$. of the solution containing the $l$-malate, to add $1 \mathrm{cc}$. glacial acetic acid and $10 \mathrm{cc}$. of $14 \cdot 2 \%$ ammonium molybdate solution [see also Woolf, 1929], to filter and examine the solution polarimetrically in either a $1 \mathrm{dm}$. or a $2 \mathrm{dm}$. tube, using the mercury green line. When certain bacteria are being used, filtration after adding acetic acid and molybdate does not always give a clear solution-it is necessary then to centrifuge the solutions. 
When using dyestuffs, the main difficulty is to remove the dyestuffs without affecting the content of $l$-malate. This, however, is easily accomplished, for all the dyes I have used, by shaking the solution, after addition of acetic acid and molybdate, with about $0 \cdot 25 \mathrm{~g}$. of decolorising charcoal. On filtering, a clear solution is obtained which is free from the dyestuff. Under these conditions the charcoal has an inappreciable effect on the $l$-malate content.

In the experiments to be recorded the enzyme is placed in presence of $0.08 M$ solution of sodium fumarate and incubation allowed to proceed at $45^{\circ}$. The rate of transformation of the fumarate into $l$-malate is linear for about $50 \%$ of its transformation into the equilibrium concentration of $l$-malate. (Equilibrium is established at a ratio of about 1 fumarate to $3 l$-malate.)

Using a $1 \mathrm{dm}$. tube, the rotation given, under the conditions specified, by a $0.08 M$ solution of fumarate which has reached equilibrium in the presence of fumarase at $45^{\circ}$, is $2 \cdot 32^{\circ}$. The transformation of fumarate into $l$-malate is linear until the rotation begins to exceed $1 \cdot 2^{\circ}$. Hence for studying the effects of various dyes, etc., on fumarase, an amount of enzyme was taken, which would give in the time of experiment, and in the presence of $0.08 M$ fumarate, a rotation of about $1 \cdot 2^{\circ}$.

2 cc. of the brain extract, prepared as described above, was found to give in the presence of $0.08 M$ fumarate and $M / 25$ phosphate buffer, $p_{\mathrm{H}} 7 \cdot 4$, a rotation of $1.0^{\circ}$ in 2 hours at $45^{\circ}$. The activity of the fumarase in the extract, after submitting it to the action of dyes, etc., could be easily estimated, therefore, by determining the rotation under these experimental conditions. A rotation, for instance, of $0.5^{\circ}$ would mean that an inhibition of $50 \%$ of the activity of the enzyme had occurred.

\section{Effects of dyestuffs on fumarase from brain.}

Table I gives a representative series of results illustrating the action of dyestuffs at a fairly high concentration (1/2000) on the fumarase in brain

Table I. Effects of dyestuffs (1/2000) on fumarase from brain in the presence of phosphate buffer, $\mathrm{p}_{H} \% \cdot 4$, at $45^{\circ}$.

\begin{tabular}{lrlr}
\multicolumn{1}{c}{ Dyestuff } & $\%$ inhibition & \multicolumn{1}{c}{ Dyestuff } & $\%$ inhibition \\
Congo red & 100 & Neutral red & 0 \\
Benzopurpurin & 100 & Janus green & 81 \\
Trypan blue & 100 & Safranine & 4 \\
Water blue & 67 & Methylene violet & 4 \\
Acid green & 100 & Bismarck brown & 0 \\
Crystal scarlet & 5 & Acriflavine & 12 \\
Orange G & 0 & Eosin & 51 \\
Methyl violet $6 \mathrm{~B}$ & 100 & Erythrosin & 100 \\
Ethyl violet & 100 & Pyronine & 0 \\
Brilliant green & 0 & Methylene blue & 0 \\
Malachite green & 38 & Toluidine blue & 9
\end{tabular}

extract. The experiments were carried out as follows. In each of a series of tubes were placed 2 cc. brain extract, 1 cc. $M / 5$ phosphate buffer, $p_{\mathrm{H}} 7 \cdot 4$, and $1 \mathrm{cc}$. of an aqueous solution of dyestuff. The tubes were placed in a waterbath kept at $45^{\circ}$ for 30 minutes, and then 1 cc. of a $0.4 M$ solution of sodium 
fumarate was added to each tube. They were replaced in the bath for two hours, and then $1 \mathrm{cc}$. glacial acetic acid and $10 \mathrm{cc}$. of the ammonium molybdate solution were added to each tube. The malic acid was estimated polarimetrically in a $1 \mathrm{dm}$. tube after adding a little charcoal to each solution, shaking and filtering. Table I gives the percentage inhibitions of activity effected by each dyestuff on a particular extract. It is important, as will be explained presently, when comparing the inhibitions produced by various dyestuffs to use one extract for making the comparison.

It is evident from these results that both acid and basic dyestuffs are toxic to fumarase at a concentration of $1 / 2000$ and $p_{\mathrm{H}} 7 \cdot 4$. There is, however, a marked specificity in action both among the acid and basic dyestuffs. Thus neutral red is inert but Janus green fairly toxic; orange $G$ is inert but Congo red highly toxic.

It is interesting to compare these results with those obtained when studying the action of dyestuffs on oxidations [Quastel and Wheatley, 1931]. Here none of the acid dyestuffs was highly toxic. Among the basic dyestuffs, acriflavine, safranine and brilliant green were highly toxic; yet these dyestuffs have no effect on fumarase under the conditions employed.

\section{Effects of dyestuffs at various concentrations on fumarase.}

It is possible to obtain a better idea of the relative toxicities of the dyestuffs by studying their action at different concentrations. Table II shows the effects of a number of dyestuffs at considerable dilution, the experiments being carried out in the manner described above and upon one extract from brain.

Table II. Percentage inhibitions effected by dyestuffs at varying concentrations on fumarase (in presence of phosphate buffer, $\mathrm{p}_{H} \mathrm{\%} \cdot 4$, at $45^{\circ}$ ).

\begin{tabular}{lcccc} 
& \multicolumn{4}{c}{ Concentration of dyestuff } \\
Dyyestuff & $1 / 16,000$ & $1 / 32,000$ & $1 / 64,000$ & $1 / 128,000$ \\
Congo red & 100 & 100 & 100 & 100 \\
Benzopurpurin & 100 & 100 & 100 & 100 \\
Trypan blue & 100 & 100 & 92 & 52 \\
Methylene blue & 12 & 0 & 0 & 0 \\
Toluidine blue & 10 & 6 & 0 & 0 \\
Methyl violet & 96 & 40 & 16 & 0 \\
Ethyl violet & 100 & 100 & 81 & - \\
Crystal violet & 82 & 21 & 0 & 0 \\
Gentian violet & 51 & 25 & 6 & 0 \\
Brilliant green & 7 & 0 & 0 & 0 \\
Malachite green & 20 & 10 & 0 & 0 \\
Water blue & 34 & 13 & 0 & 0 \\
Neutral red & 2 & 0 & 0 & 0 \\
Janus green & 48 & 8 & 0 & 0 \\
Erythrosin & 91 & 57 & 25 & 20
\end{tabular}

It is immediately clear that the dyestuffs most toxic at low concentrations belong to the Congo red series, viz. Congo red, benzopurpurin, trypan blue. Among the basic dyestuffs, those belonging to the triphenylmethane series are the most toxic, but these are not so active as the Congo red series. The acid dyestuffs of the triphenylmethane series, e.g. water blue, soluble blue, acid 
green have a considerable toxicity but they are less active than the basic representatives. Erythrosin has a toxicity decidedly greater than that of eosin.

It is of interest to consider further the specificity of action of the dyestuffs. Let us compare Congo red (I), orange G (II), crystal scarlet (III) and Bismarck brown (IV).

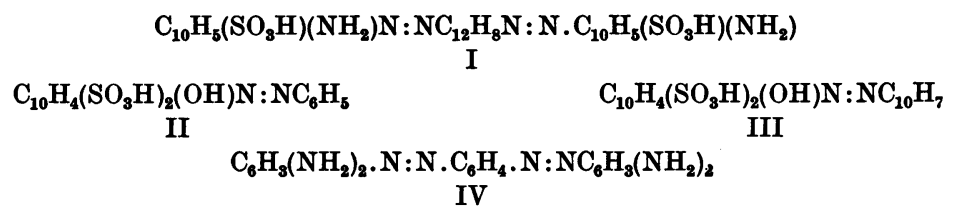

Whereas I is highly toxic, II, III and IV are inert under the conditions employed.

It is evident that the toxicity of I does not reside simply in its possession of sulphonic groups, or of amino-groups, or of the azo- or tetrazo-groups; nor is it likely that the size of the molecule is alone responsible. Possibly the benzidine nucleus is the effective group, but I have investigated the toxicity of benzidine itself and find it to be inert at a concentration of 1/1000. It would appear, therefore, that toxicity lies not in the possession of any simple grouping but on the arrangement of the molecule as a whole. The facts that benzopurpurin and trypan blue are also toxic indicate the great importance of the spatial arrangement of the groupings within the molecules-toxicity is conferred not by any single grouping in the molecule but by the relative arrangement of a number of groupings to each other.

It is evident that the toxicity of dyestuffs to the enzyme is of much the same type as that of dyestuffs and drugs to the living cell. The fact that enzymes can be so much more easily studied than the cell as a whole should be of considerable help in elucidating the factors determining toxicity of dyestuffs and drugs to the activities of the cell.

\section{Effects of dyestuffs on fumarase extracted from bacteria.}

The effects of dyestuffs upon fumarase prepared from B. coli and M. lysodeikticus in the manner described above are much the same as upon brain fumarase. The order of toxicities is similar. Methylene blue and toluidine blue, however, which have little toxic action on brain fumarase even at as high a concentration as $1 / 2000$, will, at a concentration of $1 / 5000$ entirely inhibit the fumarase prepared from B. coli or M. lysodeikticus. I have, so far, failed to discover the reason for this difference. On the whole, the fumarase from bacteria appears to be more sensitive to the action of dyestuffs than the preparation from brain. It seems probable that the differences between the extracts are due to differences in the nature of the substances accompanying the fumarase rather than to differences in the constitution of the fumarase prepared from differing biological sources. This, however, is a matter for further investigation. 


\section{Effects of dyestuffs on fumarase from blood.}

The addition of dyestuffs appears to have no inhibiting action on the activity of the enzyme prepared from blood. Congo red, benzopurpurin, trypan blue, methyl violet, at concentrations as high as $1 / 5000$ are without effect. It will be shown later that this inactivity of the dyes is due to the presence in the preparation of large quantities of protein.

\section{Effects of the addition of mixtures of dyes to brain fumarase.}

If a mixture of Congo red and methyl violet at the same concentrations be added to fumarase under the conditions described above, there is practically no toxic effect-though either of the dyestuffs alone is highly toxic at the concentration used. This result applies to many mixtures of dyestuffs. For instance, the mixtures of Congo red with crystal violet, methylene violet, methylene blue, or malachite green (where each constituent was at a concentration of 1/5000) gave percentage inhibitions of 14, 0,5 and 6 respectivelythe Congo red alone giving $100 \%$ inhibition. On the other hand, mixtures of Congo red with water blue, crystal scarlet, or orange $G$ were as toxic as Congo red itself.

Now it is observed that whenever a mixture of toxic dyestuffs is inert, a precipitate is formed-this being a compound or adsorption complex of the two dyestuffs. It seems that, in nearly all instances, the mixture of acid dyestuff and basic dyestuff forms a compound which is inert so far as its effect upon fumarase is concerned. On the other hand, a mixture of two acid dyestuffs or two basic dyestuffs is not less toxic than the more active of the two dyestuffs present.

The fact that acid and basic dyestuffs neutralise each other's toxic effects makes it evident that the acid or basic nature of the dyestuffs is a factor primarily involved in the combination with, or adsorption upon, the enzyme. It is clear, therefore, that the enzyme must possess acidic and basic groups (or groups bearing opposite charges), a result which is in keeping with the standpoint taken by Michaelis that an enzyme has ampholytic properties. It is significant, however, that both groups must be ionised, under the conditions of these experiments $\left(p_{\mathrm{H}} 7 \cdot 4\right)$, and it follows that the active centre, responsible for the activation of fumarate, must have a zwitterion constitution.

\section{Combination of enzyme and fumarate.}

The important question now arises as to whether the fumarate molecule is itself adsorbed or combined at the basic and acidic groups which help to make up the fumarase centre. According to the active centre hypothesis, the adsorption (or combination) and the subsequent activation of fumarate at the centre will depend on the nature and spatial arrangement of the groups composing the centre. If, therefore, as the results with dyestuffs indicate, oppositely charged groups are constituents of the enzyme, and if such groups are con- 
cerned with the adsorption and activation of the substrate molecule, the compound of fumarate with the enzyme should have the effect of preventing or inhibiting the combination of the dyestuff with the enzyme. Experiment entirely confirms this.

Exp. $A$. To 2 cc. brain extract were added 1 cc. $0 \cdot 2 M$ phosphate buffer, $p_{\text {H }} 7 \cdot 4,1$ cc. water and 1 cc. $0 \cdot 4 M$ sodium fumarate. After incubation at $45^{\circ}$ for 2 hours the rotation was $1.23^{\circ}$.

To 2 cc. brain extract were added 1 cc. $0 \cdot 2 M$ phosphate buffer, $p_{\mathrm{H}} \mathbf{7 \cdot 4}$, 1 cc. $1 / 3000$ methyl violet solution and 1 cc. $0 \cdot 4 M$ sodium fumarate. After incubation at $45^{\circ}$ for 2 hours the rotation was $1 \cdot 22^{\circ}$.

To 2 cc. brain extract were added 1 cc. $0 \cdot 2 M$ phosphate buffer, $p_{\mathrm{H}} \mathbf{7 \cdot 4}$, and $1 \mathrm{cc} .1 / 3000$ methyl violet solution. This mixture was allowed to incubate at $45^{\circ}$ for 30 minutes, and then 1 cc. $0.4 M$ sodium fumarate was added. After incubation at $45^{\circ}$ for 2 hours the rotation was $0.56^{\circ}$.

This experiment shows that incubation with methyl violet for 30 minutes prior to the addition of fumarate gave an inhibition of $54 \%$, whereas when the methyl violet was added together with the fumarate, no inhibition was effected.

Exp. B. The experiment was carried out as above but instead of methyl violet solution there was added $1 \mathrm{cc}$. $1 / 27,000$ Congo red. The addition of fumarate together with the dye resulted in no inhibition of the enzyme; previous incubation for 30 minutes before the addition of the fumarate resulted in an inhibition of $53 \%$.

It is important, of course, in carrying out these experiments not to have too high concentrations of dyestuffs. The higher the concentration of dyestuff, the more difficult it is to observe the 'protective' action of the fumarate.

The experiments show that fumarate prevents the combination of both acid and basic dyestuffs at the enzyme. It would be expected, therefore, that the fumarate molecule is so arranged in its combination with the enzyme that it bridges both the acid and the basic groups. This arrangement (Fig. 1) of the fumarate molecule across two oppositely charged groups provides the mechanism required to polarise the double bond, this polarisation being necessary before activation can occur [Quastel, 1926]. Adsorption of the fumarate molecule is

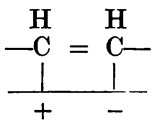

Fig. 1. not in itself sufficient to bring about activation, for it is known that the fumarate molecule is absorbed at surfaces [Phelps, 1929], and there is no evidence that transformation to malic acid occurs. The fact, however, that the enzyme possesses two oppositely charged groups, to both of which the fumarate molecule is attached, must result in a polarising field which, in this case, is powerful enough to give the fumarate molecule the necessary energy of activation. Following polarisation, and the resulting induction of positive and negative charges at the ends of the double bond (or of an internal shift of protons and electrons), the addition of the elements of water occurs with the formation of malic acid. 
It is obvious that the type of molecule which can be adsorbed at the fumarase centre, so as to bridge the two oppositely charged groups must be very limited; for, considering the dyestuffs alone, where each dye presumably attracts only one of the groups, the specificity of adsorption or combination is most marked. The fact that such specificity occurs among the dyestuffs must mean that there are important factors bearing upon adsorption or combination at the enzyme, other than simply the presence of the positively or negatively charged groups.

The question which now arises is whether the double bond is essential for the adsorption of the fumarate (or its arrangement across the oppositely charged groups) at the enzyme. Preliminary work has begun on this matter and it is clear that succinate will also 'protect' fumarase from toxic dyestuffs. It is hoped to communicate details of the investigation later.

\section{Effects of proteins on the toxic action of dyestuffs.}

The addition of protein (egg-white, serum, gelatin) to fumarase results in a very marked protective action against toxic dyestuffs.

To 2 cc. brain extract were added 1 cc. $0 \cdot 2 M$ phosphate buffer, $p_{\text {H }} 7 \cdot 4,1$ cc. $1 / 5$ human serum, and 1 cc. $1 / 1000$ Congo red solution. This was allowed to incubate at $45^{\circ}$ for 30 minutes, and then $1 \mathrm{cc} .0 .4 M$ sodium fumarate solution was added. After further incubation at $45^{\circ}$ for 2 hours the rotation was $0 \cdot 75^{\circ}$. In the absence of Congo red the rotation was $0: 96^{\circ}$. Serum itself has no perceptible effect on the activity of fumarase under the conditions employed.

If the serum be heated, either at $100^{\circ}$ for a few minutes or at $55^{\circ}$ for 30 minutes, there is a marked increase in the 'protective' action.

Results with human and rabbit serum are shown in Table III. Egg-white, gelatin and milk have similar protective actions.

Table III. Percentage inhibitions by dyestuffs on fumarase in the presence of sera and heated sera.

\begin{tabular}{clr} 
Dyestuff & \multicolumn{1}{c}{ Serum } & $\%$ inhibition \\
Congo red $(1 / 5000)$ & None & 100 \\
$"$, & $1 / 25$ human serum & 21 \\
$"$, & $1 / 25$ human serum heated at $100^{\circ}$ for $15 \mathrm{~min}$. & 0 \\
$"$, & $1 / 25$ rabbit serum & 65 \\
$"$, & $1 / 25$ rabbit serum heated at $100^{\circ}$ for $15 \mathrm{~min}$. & 10 \\
$"$ & $1 / 50$ rabbit serum & 80 \\
Methyl violet $(1 / 15,000)$ & $1 / 50$ rabbit serum heated at $55^{\circ}$ for $30 \mathrm{~min}$. & 29 \\
$"$ & None & 47 \\
$"$ & $1 / 50$ rabbit serum & 0 \\
& $1 / 50$ rabbit serum heated at $55^{\circ}$ for 30 min. & 0
\end{tabular}

The fact that the fumarase preparation from blood is not affected by dyestuffs is clearly due to the presence of the protein.

Now it is well known that proteins greatly diminish the activity of most antiseptics, and Hirschfelder and Wright [1930] have recently shown that the 
attachment of dyestuffs, e.g. methyl violet, to egg-albumin follows the Freundlich adsorption isotherm very closely and have adduced evidence that the reaction between the dye and the protein is a surface (adsorption) reaction and not a strictly chemical one. By dialysis experiments they were able to estimate the amount of dyestuff taken up by protein. They then studied the effects of protein in reducing the antiseptic action of dyestuffs on yeast, and found that the reduction was not as great as would be anticipated if the compound between protein and dye exerted no toxic action. They therefore concluded that the fraction of the dye which was adsorbed on the protein exerted an antiseptic action.

In a number of ways the effects of proteins on the toxic action of dyestuffs on fumarase resemble those on the antiseptic action of dyestuffs on yeast. Hirschfelder and Wright found that denatured proteins adsorb more dyestuff than native ones, and, as shown in Table III, denatured sera have a greater protective action on fumarase. The most likely explanation of the protective action of proteins on the enzyme is that the protein adsorbs or combines with the dyestuff, leaving a relatively small quantity of dyestuff free to attack the enzyme. There is no evidence from my experiments that the combination of protein and dye has any toxic action on the enzyme. It seems strange that a combination of protein and dye should exert a toxic action on the yeast cell, as Hirschfelder and Wright maintain. These workers followed the action of the dye on the $\mathrm{CO}_{2}$ production of the cell in presence of sucrose. Presumably the action of the dye occurs within the cell and if this is so, the cell membrane must be permeable to the compound of protein and dyestuff. There is, however, the possibility, it seems to me, that the presence of the protein has an effect on the permeability of the cell, making the entrance of the dyestuff easier and hence inducing a greater antiseptic action than would have been anticipated. A point in favour of this suggestion is that the yeast produces gas more freely in the presence of protein than in its absence, pointing, possibly, to an easier access of sucrose to the enzymes of the cell. This criticism is mentioned only to indicate the difficulty of interpreting results carried out on the intact cell.

Table IV. Effect of varying quantities of human serum on the toxic action of Congo red $(1 / 50,000)$ on brain fumarase, in the presence of phosphate buffer, $\mathrm{p}_{H} \% \cdot 4$, at $45^{\circ}$.

$\begin{array}{cc}\begin{array}{c}\text { Amount of serum present } \\ \text { cc. }\end{array} & \begin{array}{c}\text { Rotation observed } \\ \bullet\end{array} \\ \begin{array}{c}\text { None (control with no } \\ \text { dyestuff or serum) }\end{array} & 0.91 \\ 0 \cdot 1 & 0.91 \\ 0.05 & 0.90 \\ 0.025 & 0.77 \\ 0.0125 & 0.12 \\ 0.00625 & 0.00\end{array}$

Table IV shows the effect of varying amounts of serum on the toxic action of Congo red. It will be seen that in the presence of the larger quantities of the serum, Congo red has not the least toxic action-clearly, the compound of 
Congo red and protein is inert. It is therefore possible to estimate, by the fumarase method, the actual quantity of dye taken up by the protein. The method simply consists in determining that quantity of protein which, in presence of the dyestuff, brings about, say, a $50 \%$ diminution in the activity of the enzyme. The amount of free dyestuff which accomplishes this is known and hence knowing the original quantity of dyestuff present, a subtraction gives the amount of dyestuff combined with the protein. In this manner, it may be shown that $1 \mathrm{cc}$. human serum combines with approximately $3.5 \mathrm{mg}$. Congo red.

This method of estimating the combination of protein and dye (or drug) applies, of course, only to dyestuffs (or drugs) which are toxic to fumaraseit offers, however, definite advantages over the dialysis method.

\section{Effect of a constant amount of dyestuff on varying quantities of enzyme.}

Varying quantities of brain extract were placed in a series of tubes. To each of half of these tubes was added a quantity of Congo red to make up a final concentration of $1 / 100,000$; the other half of the tubes received no dyestuff. 1 cc. phosphate buffer, $p_{\mathrm{H}} \mathbf{7 \cdot 4}$, and variable quantities of water were added to each tube to make up the final volume to $8 \mathrm{cc}$. The tubes were incubated for 30 minutes at $45^{\circ}$, and then $2 \mathrm{cc}$. of $0.4 M$ sodium fumarate solution were added to each tube. After a final incubation for 2 hours at $45^{\circ}$, the rotations were determined on 5 cc. Results are shown in Table V.

Table V. Effect of a constant quantity of Congo red $(1 / 100,000)$ on varying quantities of fumarase from brain.

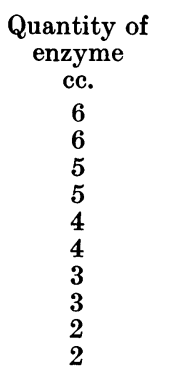

$\begin{array}{lc}\text { Dyestuff } & \begin{array}{c}\text { Rotation } \\ \text { observed }\end{array} \\ \text { Absent } & 1.52^{\circ} \\ \text { Present } & 1.25 \\ \text { Absent } & 1.30 \\ \text { Present } & 0 \cdot 85 \\ \text { Absent } & 1.06 \\ \text { Present } & 0 \cdot 40 \\ \text { Absent } & 0 \cdot 80 \\ \text { Present } & 0 \cdot 11 \\ \text { Absent } & 0.52 \\ \text { Present } & 0.00\end{array}$

\begin{tabular}{|c|c|}
\hline Inhibition & $\frac{\text { Rotation }}{\begin{array}{c}\text { Quantity of } \\
\text { enzyme }\end{array}}$ \\
\hline & 0.25 \\
\hline $0.27^{\circ}$ & 0.21 \\
\hline - & $0 \cdot 26$ \\
\hline 0.45 & $0 \cdot 17$ \\
\hline - & $0 \cdot 26$ \\
\hline 0.66 & $0 \cdot 10$ \\
\hline- & $0 \cdot 27$ \\
\hline $0 \cdot 69$ & 0.04 \\
\hline 一 & $0 \cdot 26$ \\
\hline 0.52 & 0.00 \\
\hline
\end{tabular}

It will be seen that, whereas in the absence of the dye the rotation is strictly proportional to the amount of enzyme, in the presence of the dye this proportionality entirely disappears.

It would have been anticipated that the greater the amount of enzyme, the greater the amount of combination between enzyme and dye and hence the greater the actual inhibition. The reverse of this occurs; the greater the amount of enzyme the less is the actual inhibition.

This result is easily explained if the assumption is made that the brain extract contains substances, other than the enzyme, which take up the dyestuff. The greater the amount of extract taken, the greater is the quantity of 
impurity present which takes up dyestuff, and the smaller is the amount of the free dyestuff left over to attack the enzyme. Hence as the quantity of enzyme is decreased, the greater will be the apparent inhibition induced by the dye.

This can be placed on a mathematical basis taking the standpoint that the mass action law is followed or that the adsorption law is followed. Both laws give rise to curves which approximate closely to that found by experimentbut it is difficult from the data as yet available to decide which law is, in fact, followed.

The same phenomenon occurs with other dyestuffs and it seems to be a general rule, even with the purest extracts I have been able so far to prepare, that the actual inhibition effected by a dyestuff tends to increase as the amount of extract decreases.

It is for this reason that the comparison of the action of various dyestuffs should be carried out on one particular extract.

Comparison of effects of dyestuffs on the intact cell and on the cell extract.

When a washed $B$. coli suspension is used as a source of fumarase, the effects of the dyestuffs are, in certain instances, found to be quantitatively different from the effects on brain extract. It is shown in Table I that Congo red, benzopurpurin, methyl violet, ethyl violet and erythrosin at a concentration of $1 / 2000$ will give $100 \%$ inhibition of the activity of fumarase from brain. When a $B$. coli suspension is examined in precisely the same way as has been described for the extract, the following figures for the inhibitions are obtained (concentration of dyestuff, 1/2000).

$\begin{array}{lllllll}\text { Methyl violet } & \ldots & 100 \% & \text { Congo red } \ldots & \ldots & 56 \% \\ \text { Ethyl violet } & \ldots & 100 \% & \text { Benzopurpurin } & \ldots & 38 \% \\ & & & & \text { Erythrosin } \ldots & \ldots & 58 \%\end{array}$

Thus, with a $B$. coli suspension the Congo red dyes are not as effective as the triphenylmethane series at these high concentrations.

When, however, an extract of fumarase is made from $B$. coli the dyestuffs show the same order of toxicity as with the brain extract.

A thick suspension of freshly grown and washed $B$. coli was incubated overnight at $37^{\circ}$ with twice its volume of $1 \% \mathrm{Na}_{2} \mathrm{HPO}_{4}$. It was then centrifuged and the centrifugate (or extract) separated from the deposit; the latter was made into a suspension with normal saline. Both the extract and the suspension were brought to $p_{\mathrm{H}} \mathbf{7 \cdot 4}$. The suspension of the intact cells had about twice the furmarase activity of the extract. The effects of dyestuffs on the extract and on the suspension of intact cells were then compared-amounts of extract and suspension being taken so that they had equal fumarase activity. The results are shown in Table VI. It will be seen that, whereas methyl violet and water blue had practically the same effect on the intact cell 
as on the extract, Congo red and toluidine blue were decidedly less toxic to the cells.

Table VI. Comparison of percentage inhibitions effected by dyestuffs on fumarase in the cell extract and in the intact cell (B. coli).

Dyestuff $(1 / 5000)$
Congo red
Methyl violet
Water blue
Toluidine blue

$\begin{array}{cc}\text { Intact cell } & \text { Cell extract } \\ 59 & 97 \\ 88 & 82 \\ 56 & 57 \\ 56 & 90\end{array}$

The most probable explanation of these results is that the bacterial cell has a much greater permeability to methyl violet and water blue than to Congo red or toluidine blue.

It would seem that the $B$. coli cell is almost freely permeable to members of the triphenylmethane series but resistant to those of the Congo red series, to toluidine blue and to erythrosin.

\section{Reversibility of the compound of enzyme and dyestuff.}

Very little success has so far attended efforts to remove the dyestuff from its combination with the enzyme.

Two methods have been tried.

(1) To the mixture of enzyme and toxic dyestuff which had been allowed to incubate at $45^{\circ}$ for 30 minutes, there was added another dyestuff, sufficient in amount to combine with the toxic dyestuff present. The effect of the second dyestuff should be to increase the activity of the enzyme by removing the first dyestuff combined with it. Congo red and methyl violet were used in such concentrations that when added together no inhibition of the enzyme was effected. On adding the methyl violet, however, after the Congo red had been in contact for 30 minutes with the enzyme, the toxic effect of the latter was not appreciably decreased-the inhibition was $92 \%$.

(2) To the mixture of enzyme and Congo red, after incubation at $45^{\circ}$ for 30 minutes there was added 1 cc. serum-an amount which would protect the enzyme from a considerable quantity of the dyestuff. A slight increase in the activity of the enzyme resulted. The inhibition without the serum was $100 \%$; the inhibition after the subsequent addition of serum was $79 \%$. Clearly, a slight reversibility was effected.

It is evident from these facts that the combination between enzyme and dyestuff is very strong and offers a striking contrast to that between the enzyme and its substrate (fumarate) where an easy reversibility must occur.

\section{Effects of phosphates on fumarase.}

In view of the action of phosphates on the toxicity of dyestuffs on the oxidations of bacteria and tissues [Quastel and Wheatley, 1931] it was of interest to investigate the influence of phosphates on the effects of dyestuffs 
on fumarase. Now it has been shown by Clutterbuck [1928] and later by Mann and Woolf [1930] that phosphates increase the velocity of fumarate transformation by fumarase. On making a quantitative comparison of the action of phosphates on fumarase in $B$. coli and in brain extract (containing initially less than $0.02 \mathrm{mg}$. $\mathrm{P}$ per cc.), it was found that the effects were not identical. Whereas phosphates at a concentration of $0.04 M$ and $p_{\mathbf{H}} 7 \cdot 4$, approximately doubled the rate of fumarate transformation in presence of $B$. coli (an initial concentration of $0.08 M$ fumarate being used), phosphates under the same conditions increased the rate of change in presence of brain extract in a ratio of $1 \cdot 3$. Although there is no question that phosphates increase the rate of change of fumaric acid to $l$-malic acid in presence of brain extract, the effects are apparently not as great as with intact $B$. coli. Possibly this may be due to interfering substances in the brain extract, but the criticism is justified that in work on the intact cell, as carried out by Mann and Woolf, there are also complicating factors which should be considered in drawing conclusions as to the effects of phosphates or salts on the enzyme. It seems to me, for instance, that in the work on the effects of salts, etc. on $p_{\mathrm{H}^{-}}$-activity curves using the intact cells, it is not altogether certain that the interior of the cell is at the same $p_{\mathbf{H}}$ as the external medium, especially when the latter is unbuffered.

Turning now to the question of the effect of phosphates on the action of dyestuffs, it is found that a protective action exists. The protection, however, does not seem to be as great as that observed in the case of oxidations. Methylene blue and toluidine blue (1/2000), which have little or no action on brain fumarase in the presence of phosphate $(0.04 M)$, exert inhibitions of $15 \%$ and $22 \%$ respectively in its absence. Brilliant green, however, has a very toxic action in the absence of phosphates (100\% inhibition), this being removed by the presence of phosphates. Water blue and,eosin also have smaller toxic effects in the presence of phosphate than in its absence.

Whether the phosphate acts by combining with the dyestuff or whether it acts by competing with the dye for a grouping in the enzyme is a question for futher investigation.

\section{SUMmaRY.}

1. Cell-free preparations of fumarase have been made from bacteria, red blood corpuscles and brain. A dry preparation has been made, by the use of plaster of Paris, which retains its fumarase activity at $0^{\circ}$ for several months. The enzyme can be eluted from the powder by distilled water and is almost free from proteins and phosphates.

2. The effects of dyestuffs and mixtures of dyestuffs on fumarase are described. Both acid and basic dyestuffs are toxic. Among the acid dyestuffs, those of the Congo red series and of the triphenylmethane series are toxic, the former being the most effective. Congo red is toxic at a concentration of $1 \cdot 2 \times 10^{-8} M$. 
3. The differences in action of dyestuffs on bacterial fumarase and brain fumarase are described.

4. Fumarate 'protects' the enzyme from toxic dyestuffs, e.g. Congo red or methyl violet.

5. The bearing of these facts on the constitution of the enzyme and its mode of action are discussed.

6. Proteins 'protect' fumarase from dyestuffs by combination with them, the compound of protein and dye being inert. By this means it is possible to estimate the amount of dye taken up by the protein. Denatured protein takes up more dyestuff than native protein.

7. The actual inhibition decreases as the amount of enzyme increases, when a constant amount of dyestuff is present. This is explained on the assumption that the extracts contain substances, other than fumarase, which combine with the dyestuff.

8. Differences between the intact cell $(B$. coli) and the extract from the cell are described. Permeability of the cell membrane plays an important part in determining toxicity of a dye to the enzymes of the intact cell. Whereas $B$. coli is almost freely permeable to members of the triphenylmethane series, it is resistant to Congo red, toluidine blue and erythrosin.

9. The combination of enzyme and dyestuff is not easily reversible.

10. Phosphates exert some protective action on the enzyme against toxic dyestuffs.

I wish to express my indebtedness to the Medical Research Council for a grant in aid of the equipment of this laboratory.

\section{REFERENCES.}

Auerbach and Kruger (1923). Z. Unters. Nahr. Genussm. 46, 97. Clutterbuck (1928). Biochem. J. 22, 1193.

Hirschfelder and Wright (1930). J. Pharm. Exp. Ther. 38, 411, 433.

Mann and Woolf (1930). Biochem. J. 24, 427.

Penrose and Quastel (1930). Proc. Roy. Soc. Lond. B 107, 168.

Phelps (1929). J. Chem. Soc. 1724.

Quastel (1926). Biochem. J. 20, 166.

— and Wheatley (1931). Biochem. J. 25, 629.

- and Whetham (1924). Biochem. J. 18, 519.

Woolf (1929). Biochem. J. 23, 472. 